\title{
Brainstem Infiltration Predicts Survival in Patients With High-grade Gliomas Treated With Chemoradiotherapy
}

\author{
SHIMPEI ANAMI ${ }^{1}$, JUNYA FUKAI ${ }^{2}$, MIZUKI HAMA ${ }^{1}$, AZUSA AWAYA ${ }^{1}$, TAKAYA INAGAKI ${ }^{1}$, TAKAHIRO CHIBA ${ }^{1}$, \\ YASUTAKA NODA ${ }^{1}$, YONEHIRO KANEMURA ${ }^{3,4}$, NAOYUKI NAKAO ${ }^{2}$ and TETSUO SONOMURA ${ }^{1}$ \\ ${ }^{1}$ Department of Radiology, Wakayama Medical University, Wakayama, Japan; \\ ${ }^{2}$ Department of Neurological Surgery, Wakayama Medical University, Wakayama, Japan; \\ ${ }^{3}$ Department of Biomedical Research and Innovation, Institute for Clinical Research, \\ National Hospital Organization Osaka National Hospital, Osaka, Japan; \\ ${ }^{4}$ Department of Neurosurgery, National Hospital Organization Osaka National Hospital, Osaka, Japan
}

\begin{abstract}
Background/Aim: High-grade gliomas have a poor prognosis despite standard treatment. The aim of the study was to identify new prognostic factors to select patients who need more intense treatment. Patients and Methods: Forty-three consecutive patients underwent surgery plus chemoradiotherapy for pathologically diagnosed high-grade gliomas (grade III, IV). Results: The median survival time was 989 days, and the 1-year survival rate was $87.6 \%$. Among patients with grade IV disease, the median survival time, 1-year, and 2-year survival rate were 814 days, $82.6 \%$, and $58.7 \%$, respectively. In the univariate analysis, unmethylated MGMT promoter ( $p=0.0495)$, brainstem infiltration ( $p=0.0004)$, basal ganglia as the primary lesion site $(p=0.0056)$, 3-dimensional conformal radiotherapy $(p=0.0286)$, and $<50$ Gy ( $p=0.0049)$ were associated with a poor prognosis. In the multivariate analysis, only brainstem infiltration retained significance (HR for death, 0.21; 95\% CI=0.06-0.70; $p=0.011$ ). Conclusion: Brainstem infiltration is a novel prognostic factor for poor prognosis in patients with high-grade gliomas.
\end{abstract}

High-grade gliomas account for approximately $15 \%$ of all primary brain tumours in Japan (1). They are a curative challenge with poor treatment outcomes, particularly for those classified as glioblastomas (grade IV); the 1-, 2-, and 5-year survival rates are $60 \%, 25 \%$, and $10 \%$, respectively (1). The standard treatment modality for high-grade gliomas is surgery

This article is freely accessible online.

Correspondence to: Shimpei Anami, MD, Department of Radiology, Wakayama Medical University, 811-1, Kimiidera, Wakayama, Wakayama, Japan. Tel: +81 734410605, Fax: +81 734410605, e-mail: anami131@wakayama-med.ac.jp

Key Words: Predictor of survival, high-grade glioma, brainstem infiltration, basal ganglia, MGMT promoter. followed by chemoradiotherapy (2). However, because highgrade gliomas are highly invasive, residual tumours are inevitable. The degree of surgical resection markedly affects prognosis; thus, surgery should be aimed toward the highest possible degree of resection (3). Temozolomide is the standard chemotherapeutic for high-grade gliomas (4).

Postoperative radiotherapy significantly improves the prognosis of patients with high-grade gliomas. Extended local irradiation with 60 Gy in 30 fractions is usually administered. Higher doses and better outcomes may be achieved using other protocols; these protocols are currently under investigation and include intensity-modulated radiation therapy (IMRT), stereotactic radiotherapy (SRT), heavy ion radiotherapy, and boron neutron capture therapy (BNCT) (58). Despite its usefulness, radiotherapy may not be well tolerated by and may cause serious adverse events in elderly patients and patients with a poor general condition. For these patients, the hypo-fractionated radiation method has become the standard approach as it yields fewer severe adverse effects than other methods but has the same prognostic benefit (9).

The presence of $M G M T$ promoter methylation in the tumour increases the efficacy of temozolomide and improves prognosis (10). Additional novel prognostic factors include point mutations in the $I D H$ gene and co-deletion of the short arm of chromosome 1 and the long arm of chromosome 19 (11-13). Recent advances in molecular biology have led to revision of the classification of central nervous system (CNS) tumours.

The purpose of this study was to identify new prognostic factors for high-grade gliomas.

\section{Patients and Methods}

Study design and patients. This retrospective study was approved by our institutional review board (approval number 2944) and was conducted according to the tenets of the 1964 Declaration of Helsinki and its later amendments. Written informed consent was obtained from all participants. 
Forty-four consecutive patients underwent chemoradiation at our institution between January 2014 and October 2019. Among them, one patient was excluded based on the exclusion criteria [no specific events during a follow-up of $<60$ days or a diagnosis based on magnetic resonance imaging (MRI) rather than on pathology]. As a result, 43 patients were eligible for this analysis, all of whom were pathologically diagnosed with high-grade gliomas at our institution.

Our study population comprised 19 men and 24 women, with a median age of 62 years (range $=18-80$ years) $($ Table I). Thirty-seven patients had a good general condition, as indicated by an Eastern Cooperative Oncology Group-performance status (ECOG-PS) of 0 or 1 , and 6 patients had a poor general condition (ECOG-PS of $\geq 2$ ). Seventeen and 26 patients had World Health Organization (WHO) grade III and IV disease, respectively, and 21/22 patients had unmethylated $M G M T$ promoter tumours (cut off value for methylation: $1 \%$ ) (14). The median tumour size was $41 \mathrm{~mm}$ (range=5-92 mm). Ten patients had brainstem infiltration on MRI at the time of initial diagnosis, and two of them had the H3F3A-K27 mutation. The primary tumour location was the basal ganglia in 8 patients.

Treatment. Surgery consisted of total or subtotal resection in 28 patients and biopsy in 15 patients. All patients received temozolomide as chemotherapy. Forty-one patients underwent IMRT, and two underwent 3-dimensional conformal radiotherapy (3D-CRT). The median radiation dose was $60 \mathrm{~Gy}$ (range $=29.37-60$ Gy). The radiation treatment was hypo-fractionated in 10 patients.

Molecular diagnosis. The molecular diagnosis of all patients was performed by the Kansai Molecular Diagnosis Network for CNS Tumours (14).

Statistical analysis. Data are reported as median (range) or number (percentage). In time-to-event analyses, overall survival was calculated from the date of surgery to the date of emergence of the event. Overall survival curves were generated using the KaplanMeier method and compared using the log-rank test. Potential prognostic factors were evaluated using the Cox proportional hazards model, and the results are reported as hazard ratios and corresponding 95\% confidence intervals. Significant factors identified in the univariate analyses were included in the multivariate model. All analyses were performed using JMP software (version 14; SAS Institute, Cary, NC, USA), and differences with $p$-values $<0.05$ were considered statistically significant.

\section{Results}

Eighteen patients died of primary disease. The general condition of one of these patients deteriorated during treatment, and treatment was therefore discontinued. The median observation period for the surviving 25 patients was 492 days (range=99-1,979 days).

The median overall survival time for all patients was 989 days, and the 1- and 2-year survival rates were $87.6 \%$ and $67.3 \%$, respectively (Figure 1A). For patients with WHO grade IV disease, the median survival time was 814 days, and the 1- and 2-year survival rates were $82.6 \%$ and $58.7 \%$, respectively (Figure 1B). For patients with grade III disease, the progression-free survival rate was $64.7 \%$ at 1 year and
Table I. Clinicopathological patient characteristics ( $n=43)$.

\begin{tabular}{|c|c|}
\hline Characteristic & Value \\
\hline Age (years), median (range) & $62(18-80)$ \\
\hline \multicolumn{2}{|l|}{ Gender, $\mathrm{n}$} \\
\hline Male & 19 \\
\hline Female & 24 \\
\hline \multicolumn{2}{|l|}{ ECOG-PS, n } \\
\hline 0 & 15 \\
\hline 1 & 22 \\
\hline 2 & 2 \\
\hline 3 & 2 \\
\hline 4 & 2 \\
\hline \multicolumn{2}{|l|}{ WHO grade, $n$} \\
\hline Grade III & 17 \\
\hline Grade IV & 26 \\
\hline \multicolumn{2}{|l|}{ MGMT promoter, $\mathrm{n}$} \\
\hline Methylated & 22 \\
\hline Unmethylated & 21 \\
\hline \multicolumn{2}{|l|}{ IDH1 } \\
\hline Mutant & 10 \\
\hline Wild-type & 33 \\
\hline \multicolumn{2}{|l|}{ TERT promoter } \\
\hline Mutant & 25 \\
\hline Wild-type & 18 \\
\hline Maximum tumour diameter (mm), median (range) & $41(5-92)$ \\
\hline \multicolumn{2}{|l|}{ Brainstem infiltration } \\
\hline Yes & 10 \\
\hline No & 33 \\
\hline \multicolumn{2}{|l|}{ Primary site } \\
\hline Basal ganglia & 8 \\
\hline Others & 35 \\
\hline \multicolumn{2}{|l|}{ Extent of surgical resection } \\
\hline GTR/STR/PR & 28 \\
\hline Biopsy & 15 \\
\hline \multicolumn{2}{|l|}{ Irradiation technique } \\
\hline IMRT & 41 \\
\hline 3D-CRT & 2 \\
\hline Total prescription dose (Gy) & $60(29.37-60)$ \\
\hline Number of fractions, median (range) & $25(11-30)$ \\
\hline $\operatorname{GTV}\left(\mathrm{cm}^{3}\right)$ & $26(3-143)$ \\
\hline $\operatorname{CTV} 1\left(\mathrm{~cm}^{3}\right)$ & $144(6-408)$ \\
\hline $\operatorname{CTV} 2\left(\mathrm{~cm}^{3}\right)$ & $307(40-733)$ \\
\hline
\end{tabular}

ECOG-PS, Eastern Cooperative Oncology Group-performance status; MGMT, $O^{6}$-methylguanine-DNA methyltransferase; IDH, isocitrate dehydrogenase; TERT, telomerase reverse transcriptase; GTR, gross total resection; STR, subtotal resection; PR, partial resection; IMRT, intensity-modulated radiation therapy; 3D-CRT, three-dimensional conformal radiotherapy; GTV, gross tumour volume; CTV1, clinical target volume $1(\mathrm{GTV}+15 \mathrm{~mm})$ and cerebral oedema; CTV2, GTV/cerebral oedema $+15 \mathrm{~mm}$.

$43.7 \%$ at 2 years; for patients with grade IV disease, it was $53.7 \%$ and $35.8 \%$, respectively.

In univariate analysis, five factors negatively impacted survival: unmethylated $M G M T$ promoter $(p=0.0495)$, brainstem infiltration $(p=0.0004)$, basal ganglia as the primary lesion site $(p=0.0056), 3 \mathrm{D}-\mathrm{CRT}(p=0.0286)$, and 

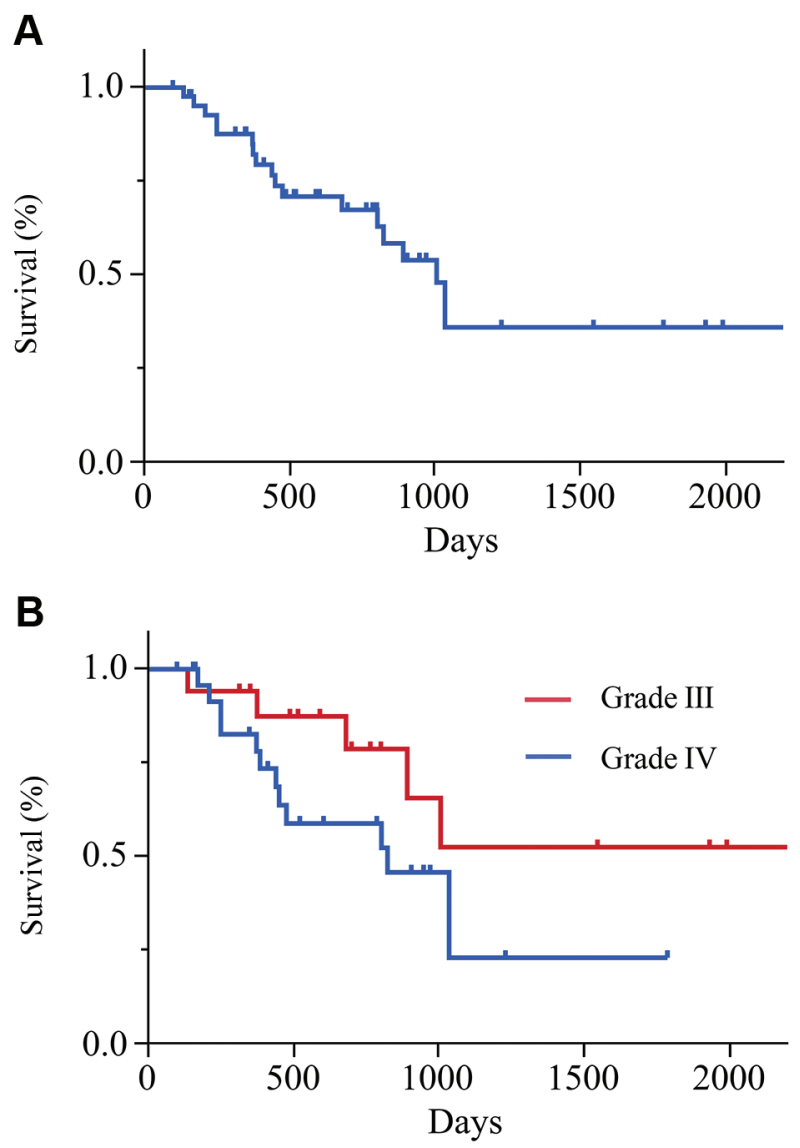

Figure 1. Overall survival after surgery. (A) In the overall cohort, the median survival time was 989 days, and the 1-and 2-year overall survival rates were $87.6 \%$ and $67.3 \%$, respectively. $(B)$ In the patients with World Health Organization grade IV tumours, the median survival time was 814 days, and the 1-and 2-year overall survival rates were $82.6 \%$ and $58.7 \%$, respectively. Meanwhile, the rates were $94.1 \%$ and $78.7 \%$, respectively, in patients with grade III tumours.

radiation dose $<50$ Gy ( $p=0.0049$ ) (Table II, Figure 2). In patients with and without brainstem infiltration, the median survival time was 363 days and 1,022 days; the 1-year survival rate, $60 \%$ and $96.7 \%$; and the 2 -year survival rate, $36 \%$ and $77.2 \%$, respectively. Age, ECOG-PS, genetic mutations other than MGMT promoter methylation, and irradiation volume (gross tumour volume and clinical target volume 1 and 2 ) had no effect on survival rates.

Because the total radiation dose was low in patients with a poor general condition and the number of 3D-CRT cases was small, only MGMT promoter methylation, brainstem infiltration, and basal ganglia as the primary lesion site were examined in the multivariate analysis. Of these, brainstem infiltration was the only significant independent predictor of poor survival (HR for death, 0.21; 95\% CI=0.06-0.70; $p=0.011$ ) (Table III).
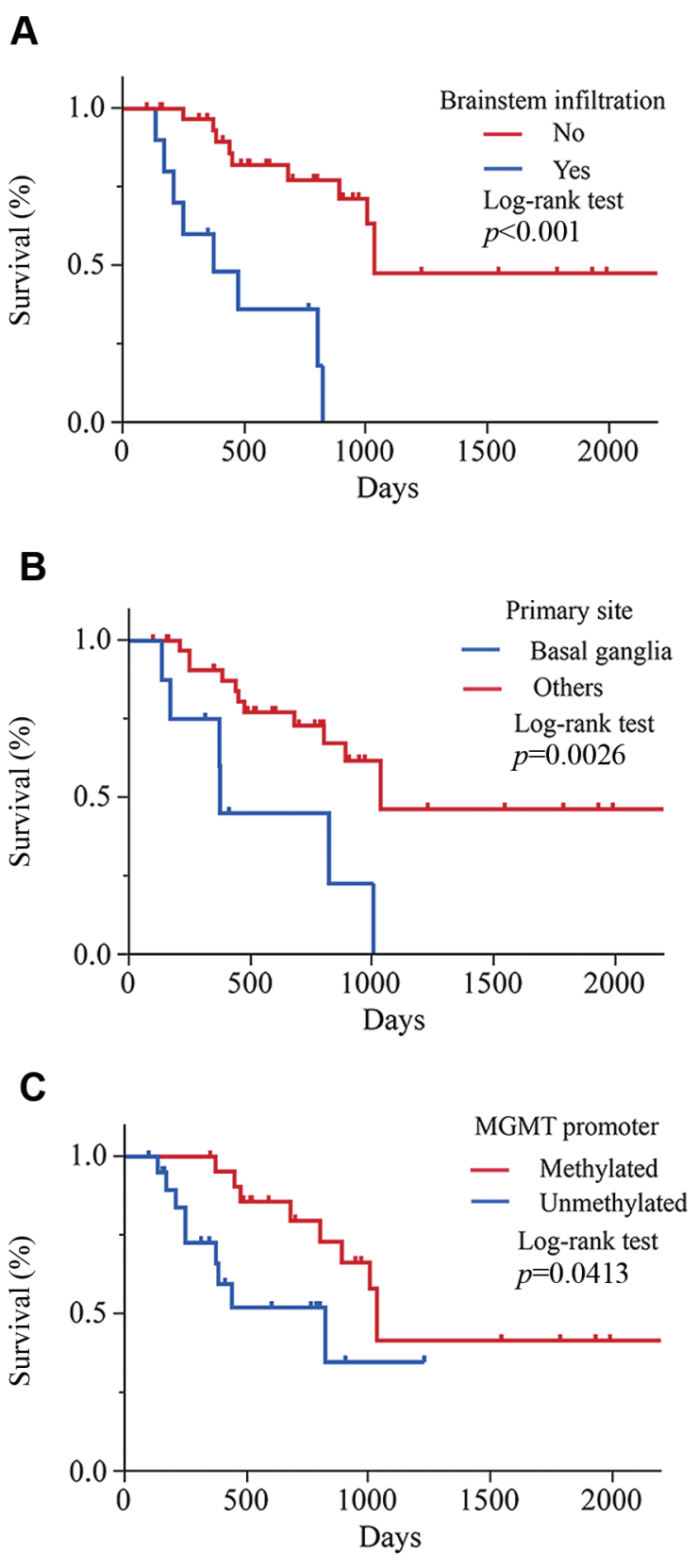

Figure 2. Postoperative survival by predictors of prognosis in the univariate analysis. Brainstem infiltration (A), basal ganglia as the primary site $(B)$, and unmethylated MGMT promoter $(C)$.

\section{Discussion}

The standard treatment modality for high-grade gliomas is surgery plus postoperative chemoradiation $(2,3)$. The prognostic factors for patients with this disease include age, Karnofsky Performance Score, surgical resection rate, and MGMT promoter methylation $(10,15)$. MGMT promoter methylation is considered a favourable prognostic factor 
Table II. Univariate analysis of the influencing factors of overall survival.

\begin{tabular}{|c|c|c|c|c|c|}
\hline \multirow[t]{2}{*}{ Clinicopathological parameter } & \multirow{2}{*}{$\begin{array}{c}\text { Patients } \\
(\mathrm{n}=43)\end{array}$} & \multicolumn{4}{|c|}{ Univariate analysis } \\
\hline & & 1-year survival rate $(\%)$ & 2-year survival rate $(\%)$ & HR $(95 \%$ CI $)$ & $p$-Value \\
\hline \multicolumn{6}{|l|}{ Age (years) } \\
\hline$<70$ & 30 & 83.3 & 60.9 & 1 & \multirow[t]{2}{*}{0.30} \\
\hline$\geq 70$ & 13 & 100.0 & 87.5 & $0.52(0.15-1.80)$ & \\
\hline \multicolumn{6}{|l|}{ Gender } \\
\hline Male & 19 & 83.3 & 66.7 & 1 & \multirow{2}{*}{0.68} \\
\hline Female & 24 & 91.1 & 66.9 & $0.82(0.32-2.10)$ & \\
\hline \multicolumn{6}{|l|}{ ECOG-PS } \\
\hline 0,1 & 37 & 91.4 & 67.9 & 1 & \multirow{2}{*}{0.10} \\
\hline $2 \sim$ & 6 & 64.3 & 64.3 & $2.61(0.84-8.16)$ & \\
\hline \multicolumn{6}{|l|}{ WHO grade } \\
\hline Grade III & 17 & 94.1 & 78.7 & 1 & \multirow[t]{2}{*}{0.14} \\
\hline Grade IV & 26 & 82.6 & 58.7 & $2.19(0.78-6.17)$ & \\
\hline \multicolumn{6}{|l|}{ MGMT promoter } \\
\hline Methylated & 22 & 100.0 & 79.6 & 1 & \multirow{2}{*}{0.0495} \\
\hline Unmethylated & 21 & 72.7 & 52.0 & $2.63(1.00-6.90)$ & \\
\hline \multicolumn{6}{|l|}{ IDH1 } \\
\hline Mutant & 10 & 100.0 & 88.9 & 1 & \multirow{2}{*}{0.16} \\
\hline Wild-type & 33 & 83.5 & 59.9 & $2.42(0.70-8.40)$ & \\
\hline TERT promoter & & & & & \\
\hline Mutant & 25 & 87.0 & 64.6 & 1 & 0.76 \\
\hline Wild-type & 18 & 88.2 & 72.2 & $1.16(0.45-3.02)$ & \\
\hline Maximum diameter of tumour & & & & & \\
\hline$\leq 40$ & 23 & 91.7 & 70.8 & 1 & 0.84 \\
\hline$>40$ & 19 & 81.3 & 61.4 & $1.10(0.43-2.80)$ & \\
\hline Brainstem infiltration & & & & & \\
\hline Yes & 10 & 60.0 & 36.0 & 1 & 0.0004 \\
\hline No & 33 & 96.7 & 77.2 & $0.14(0.05-0.41)$ & \\
\hline Primary site & & & & & \\
\hline Basal ganglia & 8 & 75.0 & 45.0 & 1 & 0.0056 \\
\hline Others & 35 & 90.6 & 72.9 & $0.234(0.08-0.65)$ & \\
\hline Extent of surgical resection & & & & & \\
\hline GTR/STR/PR & 28 & 88.5 & 65.5 & 1 & 0.65 \\
\hline Biopsy & 15 & 85.7 & 70.1 & $1.24(0.48-3.21)$ & \\
\hline Irradiation technique & & & & & \\
\hline IMRT & 41 & 89.8 & 69.0 & 1 & 0.0286 \\
\hline 3D-CRT & 2 & 0.0 & 0.0 & $15.00(1.33-169.58)$ & \\
\hline Total prescription dose (Gy) & & & & & \\
\hline$\leq 50$ & 33 & 85.7 & 28.6 & 1 & 0.0449 \\
\hline$>50$ & 10 & 87.9 & 76.9 & $0.32(0.11-0.97)$ & \\
\hline GTV volume $\left(\mathrm{cm}^{3}\right)$ & & & & & \\
\hline$\leq 30$ & 20 & 89.5 & 72.9 & 1 & 0.20 \\
\hline$>30$ & 16 & 78.6 & 50.0 & $1.92(0.71-5.23)$ & \\
\hline CTV1 volume $\left(\mathrm{cm}^{3}\right)$ & & & & & \\
\hline$\leq 150$ & 21 & 100.0 & 76.9 & 1 & 0.39 \\
\hline$>150$ & 20 & 71.1 & 53.3 & $1.53(0.58-3.98)$ & \\
\hline CTV2 volume $\left(\mathrm{cm}^{3}\right)$ & & & & & \\
\hline$\leq 300$ & 14 & 85.7 & 66.8 & 1 & 0.26 \\
\hline$>300$ & 16 & 87.5 & 80.2 & $0.49(0.14-1.68)$ & \\
\hline MIB1 index & & & & & \\
\hline$\leq 20$ & 28 & 88.3 & 66.0 & 1 & 0.62 \\
\hline$>20$ & 15 & 86.7 & 69.3 & $1.27(0.49-3.32)$ & \\
\hline Brainstem compression & & & & & \\
\hline Yes & 5 & 60.0 & 60.0 & 1 & 0.25 \\
\hline No & 38 & 91.4 & 67.9 & $0.48(0.13-1.68)$ & \\
\hline Midline shift & & & & & \\
\hline Yes & 16 & 80.4 & 62.5 & 1 & 0.55 \\
\hline No & 27 & 92.0 & 69.5 & $1.37(0.49-3.85)$ & \\
\hline Bevacizumab & & & & & \\
\hline Yes & 23 & 85.4 & 64.6 & 1 & 0.41 \\
\hline No & 20 & 90.0 & 69.3 & $0.66(0.24-1.77)$ & \\
\hline
\end{tabular}

HR, Hazard ratio; CI, confidence interval; ECOG-PS, Eastern Cooperative Oncology Group-performance status; WHO, World Health Organization; MGMT, $O^{6}$-methylguanine-DNA methyltransferase; IDH, isocitrate dehydrogenase; TERT, telomerase reverse transcriptase; GTR, gross total resection; STR, subtotal resection; PR, partial resection; IMRT, intensity-modulated radiation therapy; 3D-CRT, three-dimensional conformal radiotherapy; GTV, gross tumour volume; CTV1, clinical target volume $1(\mathrm{GTV}+15 \mathrm{~mm})$ and cerebral oedema; CTV2, GTV/cerebral oedema +15 mm; MIB1, Mind bomb 1 . 
Table III. Multivariate analysis of the influencing factors of overall survival.

\begin{tabular}{lcc}
\hline Parameter & \multicolumn{2}{c}{ Multivariate analysis } \\
\cline { 2 - 3 } & HR $(95 \% \mathrm{CI})$ & $p$-Value \\
\hline $\begin{array}{l}\text { MGMT promoter } \\
\text { Methylated }\end{array}$ & 1 & 0.55 \\
$\quad \begin{array}{l}\text { Unmethylated } \\
\text { Brainstem infiltration }\end{array}$ & $1.42(0.45-4.46)$ & 0.011 \\
$\quad$ Yes & 1 & \\
$\quad$ No \\
Primary site \\
$\quad$ Basal ganglia \\
$\quad$ Others
\end{tabular}

HR, Hazard ratio; CI, confidence interval; MGMT, $O^{6}$-methylguanineDNA methyltransferase.

because it enables a good response to temozolomide. Owing to recent advances in molecular biology, the WHO reclassified high-grade gliomas based on $I D H$ mutations, TP53 mutations, and chromosome $1 \mathrm{p} 19 \mathrm{q}$ co-deletion (16). New prognostic factors such as TERT promoter mutations have also been reported (17).

Among the genetic mutations tested in this study, only $M G M T$ promoter methylation significantly correlated with survival in the univariate analysis; it was not, however, significant in the multivariate analysis. Furthermore, patients with $I D H$ mutants tended to have a better prognosis, but the difference was not significant. We believe that significant differences may be observed by increasing the sample size or extending the observation period. Tumour factors related to tumour location, namely brainstem infiltration and basal ganglia as the primary lesion site, negatively correlated with survival in the univariate analysis; in the multivariate analysis, only brainstem infiltration retained significance. Drumm et al. reported that brainstem infiltration is a common cause of death in patients with glioblastoma, with $66 \%$ of glioblastoma patients having brainstem infiltration on autopsy (18). In their study, patients with brainstem infiltration survived significantly longer (17.4 months) than those without brain infiltration ( 9 months, $p=0.002$ ). It is thought that rapid growth of the primary lesion caused the death of the latter patients before brainstem infiltration could occur. The reason our results differ from those of Drumm et al. (18) is unclear. Possibilities include selection bias in previous studies, differences in surgical removal rates, and a higher incidence of MGMT promoter methylation in the nonbrainstem infiltration group in our study. In fact, in our study, MGMT promoter methylation was found in 2 out of 10 patients $(20 \%)$ in the brainstem infiltration group and in 20 out of 33 patients $(61 \%)$ in the non-brainstem infiltration group. Although the reason for this is not yet known, MGMT promoter methylation has been reported to be lower in brainstem gliomas, which may be similar to the results of this study $(19,20)$. Furthermore, although further studies are needed, brainstem infiltration and brainstem gliomas have low MGMT promoter methylation, which may affect the efficacy of treatment. We defined brainstem infiltration as a high fluid-attenuated inversion-recovery signal on MRI. Even small brainstem infiltrations may significantly impact prognosis; thus, local control is key to improving the prognosis of patients with high-grade gliomas.

Local control can be achieved with various treatment modalities. Tanaka et al. reported that increasing the local dose to 80-90 Gy yielded a median survival time of 16.2 months in patients with malignant gliomas (21). Iuchi et al. reported a median survival time of 20 months and improved local control rates in glioblastoma patients receiving simultaneous integrated boost-IMRT (68/40/32 Gy in 8 fractions); however, local recurrence progressed to disseminated recurrence, and the rate of brain necrosis was high $(40 \%)$ (5). Consistent with this finding, high doses of radiation were associated with brain necrosis in the study by Tanaka et al. (21).

Brainstem necrosis is the most serious and life-threatening complication in patients with brainstem infiltration. Administration of more than 60 Gy to the micro-infiltration area (brainstem) is considered dangerous and should be avoided, even if IMRT or heavy ion radiotherapy is used in addition to SRT. BNCT is the preferred primary radiotherapy technique for patients with brainstem infiltration because it delivers a high dose to tumour cells and a low dose to normal tissues. However, there have been few reports on BNCT for malignant gliomas. Yamamoto et al. reported excellent outcomes with a median survival time of 25.7 months for BNCT of primary glioblastoma and suggest that BNCT is beneficial not only in cases with brainstem infiltration, but also in those with organs subject to dose tolerance restrictions such as the optic nerve and optic chiasm (7).

Another treatment option is the concurrent use of bevacizumab during radiotherapy. Radiation-induced brain damage is caused by a vicious cycle of radiation-induced endothelial cell damage, hypoxia in peri-tumour tissues, and brain oedema and by increased expression of vascular endothelial growth factor (VEGF) (22). In the randomised trial conducted by Levin et al., bevacizumab significantly reduced the occurrence of radiation-induced brain oedema and improved clinical symptoms (23). Although this result requires verification, it suggests that the radiotherapy dose can be increased when bevacizumab is concurrently administered. Gilbert (24) and Chinot et al. (25) reported that bevacizumab and radiotherapy plus temozolomide had an additive effect on the progression-free survival rate but not on the overall survival rate in patients with glioblastoma. In 
their study, the progression-free survival rate was better in the bevacizumab group than in the placebo group during the first 2 years after treatment. Most patients with brainstem infiltration in the present study died within 2 years after treatment due to focal enlargement and thus may benefit greatly from concomitant use of bevacizumab and radiotherapy. However, bevacizumab has been shown to increase tumour invasiveness $(26,27)$, suggesting that its inhibitory effects on VEFG activity may insufficiently prevent tumour infiltration through the white matter. Therefore, bevacizumab administration must be carefully considered in cases of high-grade glioma with brainstem infiltration. In addition, although rare, brainstem gliomas have been reported in patients with neurofibromatosis type 1 , and mitogen-activated extracellular signal-regulated kinase inhibitors may be an option for these patients $(28,29)$.

Because tumour control is difficult, treatments that shorten the treatment period, such as hypo-fractionated radiation, may be useful. Hypo-fractionated delivery of $40 \mathrm{~Gy}$ is often used in elderly patients or patients with a poor general condition, as its benefits are comparable to those of standard treatments (9). Moreover, it has fewer side-effects and is thus a viable treatment option for patients with brainstem infiltration who, as shown here, have an extremely poor prognosis.

This study had certain limitations, including its retrospective design and relatively small sample size. Despite these limitations, the results clearly indicate that patients with brainstem infiltration have a poor prognosis; thus, more effective approaches to increasing the radiation dose while avoiding severe adverse effects are needed.

In conclusion, brainstem infiltration independently worsens the prognosis of patients with high-grade gliomas and thus may be a novel prognostic factor.

\section{Conflicts of Interest}

None to be declared.

\section{Authors' Contributions}

Shimpei Anami collected and analysed the data and drafted the manuscript. Shimpei Anami, Junya Fukai, Mizuki Hama, Azusa Awaya, Takaya Inagaki, Takahiro Chiba, Yasutaka Noda and Naoyuki Nakao mainly treated patients.

Junya Fukai, Yonehiro Kanemura, Naoyuki Nakao and Tetsuo Sonomura provided critical revisions of the manuscript. Junya Fukai and Tetsuo Sonomura supervised the project. All Authors read and approved the final manuscript.

\section{Acknowledgements}

The Authors would like to acknowledge Editage (www.editage.jp) for language editing.

\section{References}

1 Committee of Brain Tumor Registry of Japan: Report of brain tumor registry of Japan (2001-2004). 13th ed. Neurol Med Chir (Tokyo) 54(Suppl): 1-102, 2014.

2 The Japan Society for Neuro-Oncology: guideline for diagnosis and treatment of brain tumors, 2017. Available at: https://www.jsno.com/guideline3/CQ/002.html [Last accessed on 24th March 2021]

3 Sanai N, Polley MY, McDermott MW, Parsa AT and Berger MS: An extent of resection threshold for newly diagnosed glioblastomas. J Neurosurg 115(1): 3-8, 2011. PMID: 21417701. DOI: $10.3171 / 2011.2$.jns 10998

4 Stupp R, Hegi ME, Mason WP, van den Bent MJ, Taphoorn MJ, Janzer RC, Ludwin SK, Allgeier A, Fisher B, Belanger K, Hau P, Brandes AA, Gijtenbeek J, Marosi C, Vecht CJ, Mokhtari K, Wesseling P, Villa S, Eisenhauer E, Gorlia T, Weller M, Lacombe D, Cairncross JG, Mirimanoff RO, European Organisation for Research and Treatment of Cancer Brain Tumour and Radiation Oncology Groups and National Cancer Institute of Canada Clinical Trials Group: Effects of radiotherapy with concomitant and adjuvant temozolomide versus radiotherapy alone on survival in glioblastoma in a randomised phase III study: 5-year analysis of the EORTC-NCIC trial. Lancet Oncol 10(5): 459-466, 2009. PMID: 19269895. DOI: 10.1016/S1470-2045(09)70025-7

5 Iuchi T, Hatano K, Kodama T, Sakaida T, Yokoi S, Kawasaki K, Hasegawa Y and Hara R: Phase 2 trial of hypofractionated highdose intensity modulated radiation therapy with concurrent and adjuvant temozolomide for newly diagnosed glioblastoma. Int $\mathbf{J}$ Radiat Oncol Biol Phys 88(4): 793-800, 2014. PMID: 24495592. DOI: 10.1016/j.ijrobp.2013.12.011

6 Mizumoto M, Tsuboi K, Igaki H, Yamamoto T, Takano S, Oshiro Y, Hayashi Y, Hashii H, Kanemoto A, Nakayama H, Sugahara S, Sakurai H, Matsumura A and Tokuuye K: Phase I/II trial of hyperfractionated concomitant boost proton radiotherapy for supratentorial glioblastoma multiforme. Int J Radiat Oncol Biol Phys 77(1): 98-105, 2010. PMID: 19695794. DOI: 10.1016/j.ijrobp.2009.04.054

7 Yamamoto T, Nakai K, Kageji T, Kumada H, Endo K, Matsuda M, Shibata Y and Matsumura A: Boron neutron capture therapy for newly diagnosed glioblastoma. Radiother Oncol 91(1): 8084, 2009. PMID: 19285355. DOI: 10.1016/j.radonc.2009.02.009

8 Kawabata S, Miyatake S, Kuroiwa T, Yokoyama K, Doi A, Iida K, Miyata S, Nonoguchi N, Michiue H, Takahashi M, Inomata T, Imahori Y, Kirihata M, Sakurai Y, Maruhashi A, Kumada H and Ono K: Boron neutron capture therapy for newly diagnosed glioblastoma. J Radiat Res 50(1): 51-60, 2009. PMID: 18957828. DOI: $10.1269 /$ jrr.08043

9 Malmström A, Grønberg BH, Marosi C, Stupp R, Frappaz D, Schultz H, Abacioglu U, Tavelin B, Lhermitte B, Hegi ME, Rosell J, Henriksson R and Nordic Clinical Brain Tumour Study Group (NCBTSG): Temozolomide versus standard 6-week radiotherapy versus hypofractionated radiotherapy in patients older than 60 years with glioblastoma: the Nordic randomised, phase 3 trial. Lancet Oncol 13(9): 916-926, 2012. PMID: 22877848. DOI: 10.1016/S1470-2045(12)70265-6

10 Hegi ME, Diserens AC, Gorlia T, Hamou MF, de Tribolet N, Weller M, Kros JM, Hainfellner JA, Mason W, Mariani L, Bromberg JE, Hau P, Mirimanoff RO, Cairncross JG, Janzer RC and Stupp R: MGMT gene silencing and benefit from temozolomide in glioblastoma. N Engl J Med 352(10): 9971003, 2005. PMID: 15758010. DOI: 10.1056/NEJMoa043331 
11 Yan H, Parsons DW, Jin G, McLendon R, Rasheed BA, Yuan W, Kos I, Batinic-Haberle I, Jones S, Riggins GJ, Friedman H, Friedman A, Reardon D, Herndon J, Kinzler KW, Velculescu VE, Vogelstein B and Bigner DD: IDH1 and IDH2 mutations in gliomas. N Engl J Med 360(8): 765-773, 2009. PMID: 19228619. DOI: $10.1056 /$ NEJMoa0808710

12 Cairncross G, Wang M, Shaw E, Jenkins R, Brachman D, Buckner J, Fink K, Souhami L, Laperriere N, Curran W and Mehta M: Phase III trial of chemoradiotherapy for anaplastic oligodendroglioma: long-term results of RTOG 9402. J Clin Oncol 31(3): 337-343, 2013. PMID: 23071247. DOI: 10.1200/JCO.2012. 43.2674

13 van den Bent MJ, Brandes AA, Taphoorn MJ, Kros JM, Kouwenhoven MC, Delattre JY, Bernsen HJ, Frenay M, Tijssen CC, Grisold W, Sipos L, Enting RH, French PJ, Dinjens WN, Vecht CJ, Allgeier A, Lacombe D, Gorlia T and Hoang-Xuan K: Adjuvant procarbazine, lomustine, and vincristine chemotherapy in newly diagnosed anaplastic oligodendroglioma: long-term follow-up of EORTC brain tumor group study 26951. J Clin Oncol 31(3): 344-350, 2013. PMID: 23071237. DOI: 10.1200/ JCO.2012.43.2229

14 Sasaki T, Fukai J, Kodama Y, Hirose T, Okita Y, Moriuchi S, Nonaka M, Tsuyuguchi N, Terakawa Y, Uda T, Tomogane Y, Kinoshita $M$, Nishida N, Izumoto S, Nakajima $Y$, Arita $H$, Ishibashi K, Shofuda T, Kanematsu D, Yoshioka E, Mano M, Fujita K, Uematsu Y, Nakao N, Mori K and Kanemura Y: Characteristics and outcomes of elderly patients with diffuse gliomas: a multi-institutional cohort study by Kansai Molecular Diagnosis Network for CNS Tumors. J Neurooncol 140(2): 329339, 2018. PMID: 30076584. DOI: 10.1007/s11060-018-2957-7

15 Curran WJ Jr, Scott CB, Horton J, Nelson JS, Weinstein AS, Fischbach AJ, Chang CH, Rotman M, Asbell SO and Krisch RE: Recursive partitioning analysis of prognostic factors in three Radiation Therapy Oncology Group malignant glioma trials. J Natl Cancer Inst 85(9): 704-710, 1993. PMID: 8478956. DOI: 10.1093/jnci/85.9.704

16 Louis DN, Ohgaki H, Wiestler OD and Cavenee WK: World health organization histological classification of tumours of the central nervous system. WHO Classification of Tumours, Revised 4th Edition, Volume 1. International Agency for Research on Cancer, Lyon, 2016.

17 Arita H, Yamasaki K, Matsushita Y, Nakamura T, Shimokawa A, Takami H, Tanaka S, Mukasa A, Shirahata M, Shimizu S, Suzuki K, Saito K, Kobayashi K, Higuchi F, Uzuka T, Otani R, Tamura K, Sumita K, Ohno M, Miyakita Y, Kagawa N, Hashimoto N, Hatae R, Yoshimoto K, Shinojima N, Nakamura H, Kanemura Y, Okita Y, Kinoshita M, Ishibashi K, Shofuda T, Kodama Y, Mori K, Tomogane Y, Fukai J, Fujita K, Terakawa Y, Tsuyuguchi N, Moriuchi S, Nonaka M, Suzuki H, Shibuya M, Maehara T, Saito N, Nagane M, Kawahara N, Ueki K, Yoshimine T, Miyaoka E, Nishikawa R, Komori T, Narita Y and Ichimura K: A combination of TERT promoter mutation and MGMT methylation status predicts clinically relevant subgroups of newly diagnosed glioblastomas. Acta Neuropathol Commun 4(1): 79, 2016. PMID: 27503138. DOI: $10.1186 / \mathrm{s} 40478-016-0351-2$

18 Drumm MR, Dixit KS, Grimm S, Kumthekar P, Lukas RV, Raizer JJ, Stupp R, Chheda MG, Kam KL, McCord M, Sachdev S, Kruser T, Steffens A, Javier R, McCortney K and Horbinski $\mathrm{C}$ : Extensive brainstem infiltration, not mass effect, is a common feature of end-stage cerebral glioblastomas. Neuro Oncol 22(4): 470-479, 2020. PMID: 31711239. DOI: 10.1093/neuonc/noz216
19 Reyes-Botero G, Giry M, Mokhtari K, Labussière M, Idbaih A, Delattre JY, Laigle-Donadey F and Sanson M: Molecular analysis of diffuse intrinsic brainstem gliomas in adults. J Neurooncol 116(2): 405-411, 2014. PMID: 24242757. DOI: 10.1007/s11060-013-1312-2

20 Oka H, Utsuki S, Tanizaki Y, Hagiwara H, Miyajima Y, Sato K, Kusumi M, Kijima C and Fujii K: Clinicopathological features of human brainstem gliomas. Brain Tumor Pathol 30(1): 1-7, 2013. PMID: 22484454. DOI: 10.1007/s10014-012-0099-8

21 Tanaka M, Ino Y, Nakagawa K, Tago M and Todo T: High-dose conformal radiotherapy for supratentorial malignant glioma: a historical comparison. Lancet Oncol 6(12): 953-960, 2005. PMID: 16321763. DOI: 10.1016/S1470-2045(05)70395-8

22 Nonoguchi N, Miyatake S, Fukumoto M, Furuse M, Hiramatsu R, Kawabata S, Kuroiwa T, Tsuji M, Fukumoto M and Ono K: The distribution of vascular endothelial growth factor-producing cells in clinical radiation necrosis of the brain: pathological consideration of their potential roles. J Neurooncol 105(2): 423431, 2011. PMID: 21688077. DOI: 10.1007/s11060-011-0610-9

23 Levin VA, Bidaut L, Hou P, Kumar AJ, Wefel JS, Bekele BN, Grewal J, Prabhu S, Loghin M, Gilbert MR and Jackson EF: Randomized double-blind placebo-controlled trial of bevacizumab therapy for radiation necrosis of the central nervous system. Int J Radiat Oncol Biol Phys 79(5): 1487-1495, 2011. PMID: 20399573. DOI: 10.1016/j.ijrobp.2009.12.061

24 Gilbert MR, Dignam JJ, Armstrong TS, Wefel JS, Blumenthal DT, Vogelbaum MA, Colman H, Chakravarti A, Pugh S, Won M, Jeraj R, Brown PD, Jaeckle KA, Schiff D, Stieber VW, Brachman DG, Werner-Wasik M, Tremont-Lukats IW, Sulman EP, Aldape KD, Curran WJ Jr and Mehta MP: A randomized trial of bevacizumab for newly diagnosed glioblastoma. N Engl J Med 370(8): 699-708, 2014. PMID: 24552317. DOI: 10.1056/NEJMoa1308573

25 Chinot OL, Wick W, Mason W, Henriksson R, Saran F, Nishikawa R, Carpentier AF, Hoang-Xuan K, Kavan P, Cernea $\mathrm{D}$, Brandes AA, Hilton M, Abrey L and Cloughesy T: Bevacizumab plus radiotherapy-temozolomide for newly diagnosed glioblastoma. N Engl J Med 370(8): 709-722, 2014. PMID: 24552318. DOI: 10.1056/NEJMoa1308345

26 Thompson EM, Frenkel EP and Neuwelt EA: The paradoxical effect of bevacizumab in the therapy of malignant gliomas. Neurology 76(1): 87-93, 2011. PMID: 21205697. DOI: 10.1212/WNL.0b013e318204a3af

27 de Groot JF, Fuller G, Kumar AJ, Piao Y, Eterovic K, Ji Y and Conrad CA: Tumor invasion after treatment of glioblastoma with bevacizumab: radiographic and pathologic correlation in humans and mice. Neuro Oncol 12(3): 233-242, 2010. PMID: 20167811. DOI: 10.1093/neuonc/nop027

28 Fortunato JT, Reys B, Singh P and Pan E: Brainstem glioblastoma multiforme in a patient with NF1. Anticancer Res 38(8): 4897-4900, 2018. PMID: 30061266. DOI: 10.21873/ anticanres.12804

29 Ameratunga M, McArthur G, Gan H and Cher L: Prolonged disease control with MEK inhibitor in neurofibromatosis type Iassociated glioblastoma. J Clin Pharm Ther 41(3): 357-359, 2016. PMID: 26936308. DOI: $10.1111 /$ jcpt.12378

Received March 10, 2021

Revised March 26, 2021

Accepted April 5, 2021 